\title{
Changing trends in suicides using helium or nitrogen
}

\section{Roger W. Byard ${ }^{1}$ (iD}

Received: 24 July 2019 / Accepted: 7 October 2019/Published online: 25 October 2019

(C) Springer-Verlag GmbH Germany, part of Springer Nature 2019

The recent paper by Varlet et al. provided very useful guidelines for the autopsy approach and specimen analysis in cases of deaths involving helium inhalation [1]. As the authors noted deaths due to inert gas asphyxia are increasing in number, this trend was observed in an earlier Australian study which showed an increase in these deaths of $163 \%$ nationally between 2001 and 2009. The increase was attributed to access to books such as Final Exit and to various Internet sites that promote this form of self-termination [2]. A follow-up study of South Australian deaths confirmed that although the percentage of suicides due to helium inhalation was relatively low (1.8\%), the numbers had doubled between 2005 and 2009 and between 2010 and 2014 [3].

A recent development which may be of significance in the assessment of these cases, however, has been the increase in suicides due to nitrogen inhalation. For example, in South Australia in recent years although deaths due to both helium and nitrogen inhalation continued to increase (5 deaths in 2003-2007 compared to 31 deaths in 2013-2017), deaths due to helium inhalation had plateaued, with deaths due to nitrogen inhalation increasing 16-fold [4]. The change in the type of gas utilized may be because of concerns that helium could have been adulterated with oxygen or air and therefore be less effective; there may also be an increased awareness of the usefulness of nitrogen as an alternative lethal agent [4]. These data demonstrate the importance of closely monitoring trends in suicide methods as significant changes may develop quite rapidly, with more recently favored methods not lending themselves to laboratory analysis.

\section{References}

1. Varlet V, Iwersen-Bergmann S, Alexandre M, Cordes O, Wunder C, Holz $\mathrm{F}$ et al Helium poisoning: new procedure for sampling and analysis. Int J Legal Med. https://doi.org/10.1007/s00414-01902014-3

2. Austin A, Winskog C, van den Heuvel C, Byard RW (2011) Recent trends in suicides utilizing helium. J Forensic Sci 56:649-651

3. Byard RW (2017) Further observations on plastic bag asphyxia using helium gas. Aust J Forensic Sci 49:483-486

4. Byard RW (2018) Changing trends in suicides using helium or nitrogen: a 15-year study. J Forensic Legal Med 58:6-8 724

Publisher's note Springer Nature remains neutral with regard to jurisdictional claims in published maps and institutional affiliations.
Roger W. Byard

roger.byard@sa.gov.au

1 School of Medicine, Faculty of Medicine, The University of Adelaide, Level 3 Medical School North Building, Frome Rd, Adelaide 5005, Australia 